\title{
Actual problems of the design documentation development for capital repairs or reconstruction of capital structural facilities
}

\author{
Viktor Muradyan* and Ekaterina Efimenko \\ Don State Technical University, 344010, Rostov-on-Don, Russia
}

\begin{abstract}
The article discusses some urgent problems that designers face when developing design documentation for overhaul or reconstruction of capital structural facilities using the example of the object " The pool overhaul at the address: Rostov-on-Don".
\end{abstract}

\section{Introduction}

One of the main design goals is the development of a technical solution in accordance with the task (technical design assignment). At the same time, the implementation of the technical task can lead to both the overhaul of the structure and its reconstruction.

The Urban Planning Code of the Russian Federation [1] contains the following definitions (Chapter 1. Article 1):

Reconstruction of capital construction facilities (with the exception of linear facilities) changing the parameters of a capital construction facility, its parts (height, number of floors, area, volume), including superstructure, reconstruction, expansion of a capital construction facility, as well as replacement and (or) restoration of load-bearing building structures of a capital construction object, with the exception of individual elements' replacement for such structures with similar or other elements that improve the performance of such structures and (or) restoration of these elements.

Overhaul of capital construction objects (excluding linear objects) - replacement and (or) restoration of the capital construction objects' building structures or the elements of such structures, with the exception of load-bearing building structures, replacement and (or)

\footnotetext{
* Corresponding author: muradyan2007@yandex.ru
} 
restoration of engineering support systems and engineering networks - technical support of capital construction objects or their elements, as well as replacement of individual elements of load-bearing building structures with similar or other elements that improve the performance of such structures and (or) restoration of these elements.

\section{Method}

Let us consider modern methods of design solutions [2-6] on the example of the object "The pool overhaul at the address: Rostov-on-Don". Before the design solutions' development, a detailed instrumental examination was carried out in accordance with the requirements BC 13-102-2003 "Rules for Inspection of Load-Bearing Structures of Buildings and Structures" [7] and GOST 31937-2011 "Buildings and Structures. Rules for inspection and monitoring of technical condition" [8].

The pool building is a structure of brick bearing walls and precast reinforced concrete beams, floor slabs and coverings. The building has a variable number of storeys: from 1 to 3 , built in 1968. In plan, a building of complex configuration with overall dimensions in the axes $35.75 \times 25.11 \mathrm{~m}$.

Pool bowl in axes 1-9, C-D is a rectangular reinforced concrete tank. The dimensions of the pool in the plan are $24.95 \times 9.15 \mathrm{~m}$. It is made of monolithic reinforced concrete of class $\mathrm{B} 25$. The bottom of the tank is a monolithic ribbed floor consisting of a $300 \mathrm{~mm}$ thick slab, secondary and main beams. The main beams, in turn, rest on a grid of columns. Columns are reinforced concrete monolithic $\sim 500 \times 500 \mathrm{~mm}$. The walls of the bowl are reinforced concrete of variable thickness (thickened at the bottom and $\sim 200 \mathrm{~mm}$ at the top at the level of the side of the pool). The foundations are free-standing, stepped. The pool bowl has a deep-water part with a depth of $4.35 \mathrm{~m}$ and a shallow part, a depth of $1.6 \mathrm{~m}$ (to the top of the side).

\section{Results and discussion}

Significant defects and damage recorded during the survey - significant damage to the reinforcement by corrosion from 40 to $90 \%$ of the cross-sectional area. In addition, it should be noted that the protective layer of concrete in the walls is peeling off. In the cantilever beams of the deep-water part, cracks with an opening from 0.3 to $1.0 \mathrm{~mm}$ were recorded. This characterizes the destruction of these cantilever beams from the acting load. Reinforcement corrosion is on average up to $30 \%$, which makes the periodic profile of the reinforcement indistinguishable. Destruction of the protective layer of concrete and corrosion of reinforcement of monolithic structures adjacent to the pool bowl. 

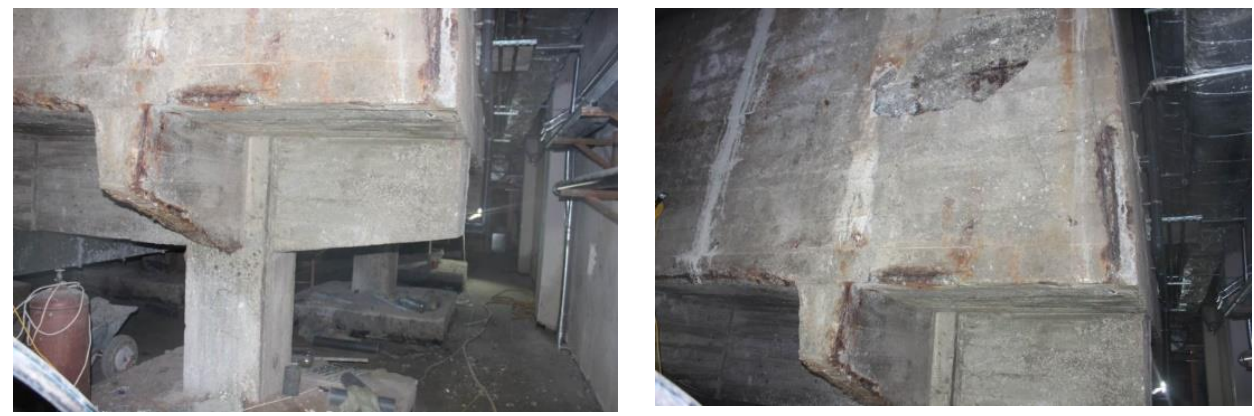

Fig. 1 and 2. General view of the pool bowl structure.

In the course of the survey, another reason for the violation of the concrete structure was discovered - physical corrosion of the reinforcement.

Reinforcement corrosion in the concrete body was influenced by the following factors:

- neutralization of calcium oxide hydrate in a humid alkaline environment with airborne vapors (CO2). At the same time, reaching the reinforcement, carbonization transfers the steel into an active state, and the oxygen entering the concrete from the moisture ensures the corrosion process flowing according to the electrochemical principle;

- corrosion destruction of reinforcement due to de-passivation of reinforcing steel under the influence of chlorine ions (Cl-).

The greatest corrosion destruction can be observed on the end wall, side walls of the deep-water part of the pool bowl.

Thus, the corrosive destruction of reinforcing steel was the result of the combined action of neutralization of the concrete moisture-alkaline environment (carbonization as a continuous process) and de-passivation of reinforcing steel due to the effect of chlorine ions contained in the water of the pool bowl (continuous process).

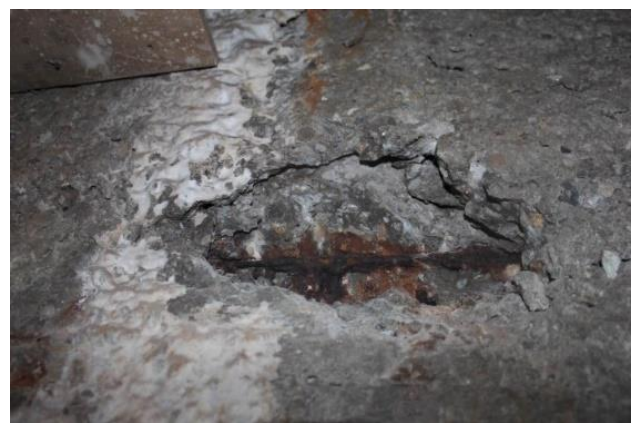

Fig. 3. Opening the bowl structure from the side to determine the existing pool bowl reinforcement state.

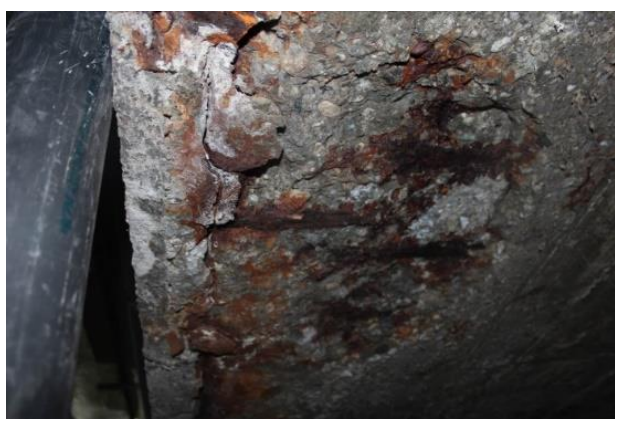

Fig. 4. Opening the structure of the pool bowl from the bottom side to determine the existing reinforcement state. 
The main reason for the existing defects in the pool bowl structures is massive and regular leaks caused by a malfunction of the waterproofing.

Lack of the pool technical operation system in general and the pool bowl in particular is observed. With an established system of operation, attention would be paid to the state of the pool bowl (commissioned in 1968) and appropriate timely measures could be taken.

As a result of assessing the technical condition of the monolithic reinforced concrete basin of the pool, based on the results analysis of a detailed (instrumental) survey, it was found that the supporting structures of the basin (walls, bottom, beams, columns) have defects and damage that do not meet the requirements of construction rules and regulations. The technical condition of the pool bowl was recognized as emergency. Particular attention should be paid to the fact that the emergency state is characterized by damage and deformations, which can lead to a sharp decrease in the bearing capacity, the collapse of individual structures.

In connection with the actual technical condition, working drawings were developed to strengthen the pool bowl.

The pool bowl overhaul includes:

- cleaning the surface of the bottom, walls, beams and columns of the pool bath from peeling concrete, removing the screed from the cut-off surface of the foundation, cleaning the reinforcement corrosion products from;

- $\quad$ repair with restoration of the structures' geometric dimensions;

- mesh fixing 3/3/100/100 Vr I on the surface of reinforced structures (bottom and walls);

- $\quad$ application of the repair compound in a layer $\approx 30 \mathrm{~mm}$ under the rule on the walls and bottom, with a view to the subsequent tight fit of the steel sheet $(\mathrm{S}=495 \mathrm{~m} 2)$;

installation of reinforcement elements RE-3; RE-3'; RE-3a; RE-8; RE-8' in the design position, installation of the support sheets of these elements on the freshly laid solution for a snug fit;

- installation of reinforcement elements in the design position RE-12 (support beams);

installation of reinforcement elements RE-2 to the design position, welding along the perimeter of the contact zone with the support beams RE-112;

- installation of reinforcement elements RE-1; RE-1'; RE-6; RE-0 followed by welding along the perimeter of contact with downstream structures;

- installation of bottom reinforcement sheets and at the same time installation of bottom reinforcement beams RE-4, RE-5, RE-7;

- installation of sheets for strengthening the walls of the bowl and at the same time installing beams to strengthen the walls on the supports RE-1; RE-1'; RE-2; RE-6; RE-9 followed by welding along the contact zone perimeter;

welding of reinforcement ribs at the installation site after the installation of supporting structures (bottom and walls);

- $\quad$ strengthening of the angular zones of deep and shallow water parts; 
- fire-retardant treatment of metal structures with a composition with a preliminary primer;

- $\quad$ dismantling / restoration work:

- dismantling of a ventilated facade;

- dismantling of brickwork;

- $\quad$ installation of brickwork;

- $\quad$ ventilated facade arrangement.

Let us consider some of the above-listed design solutions:

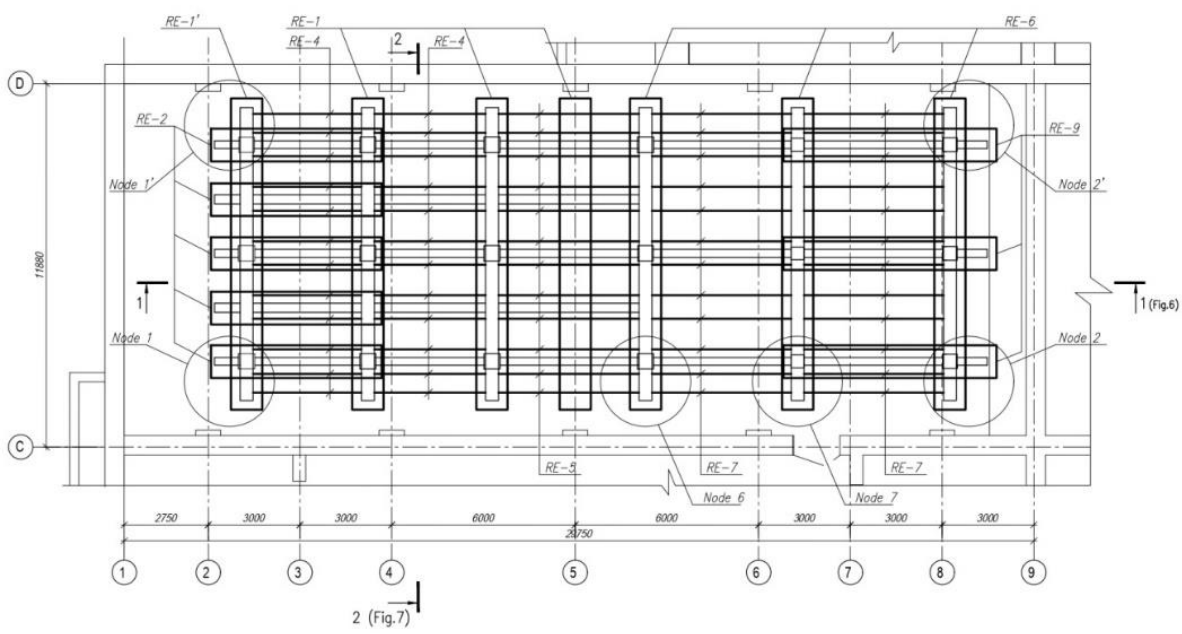

Fig. 5. Layout of amplification elements.

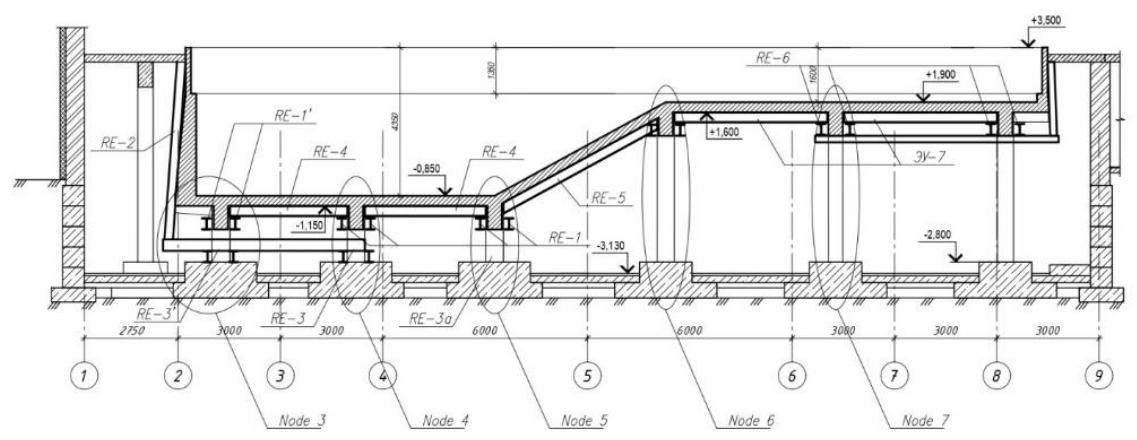

Fig. 6. Section 1-1. 


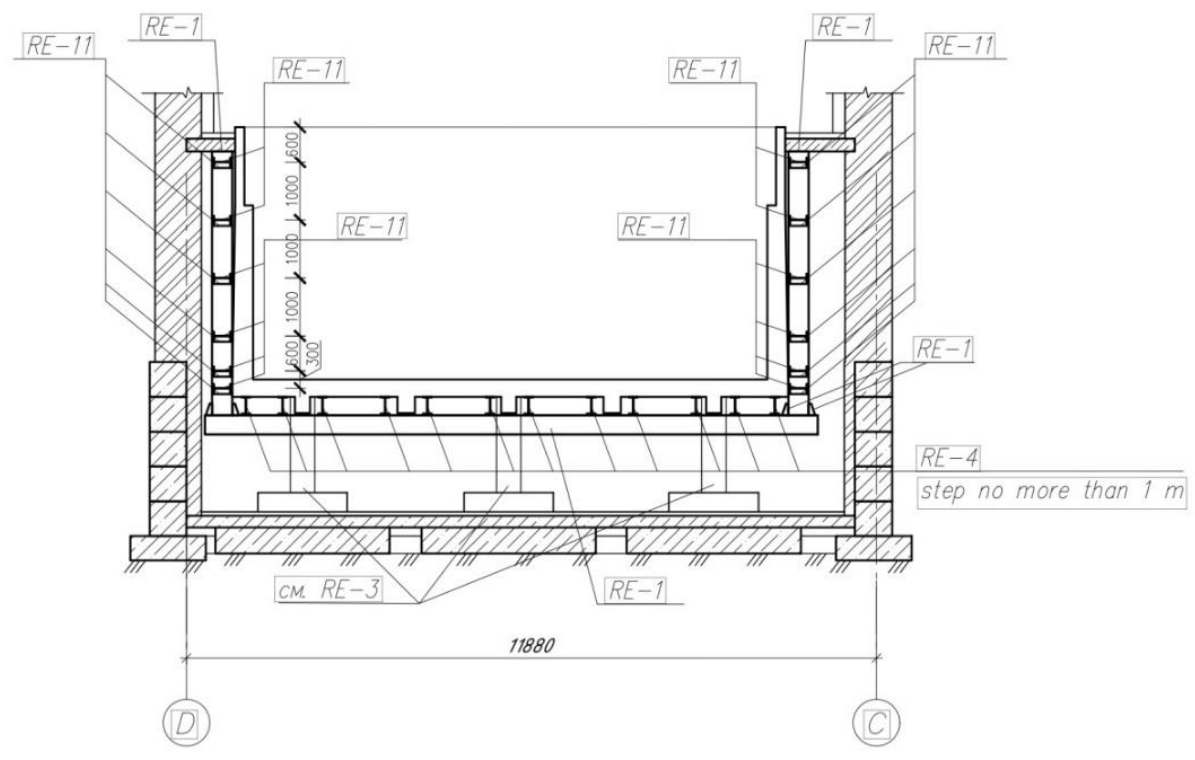

Fig. 7. Section 2-2.

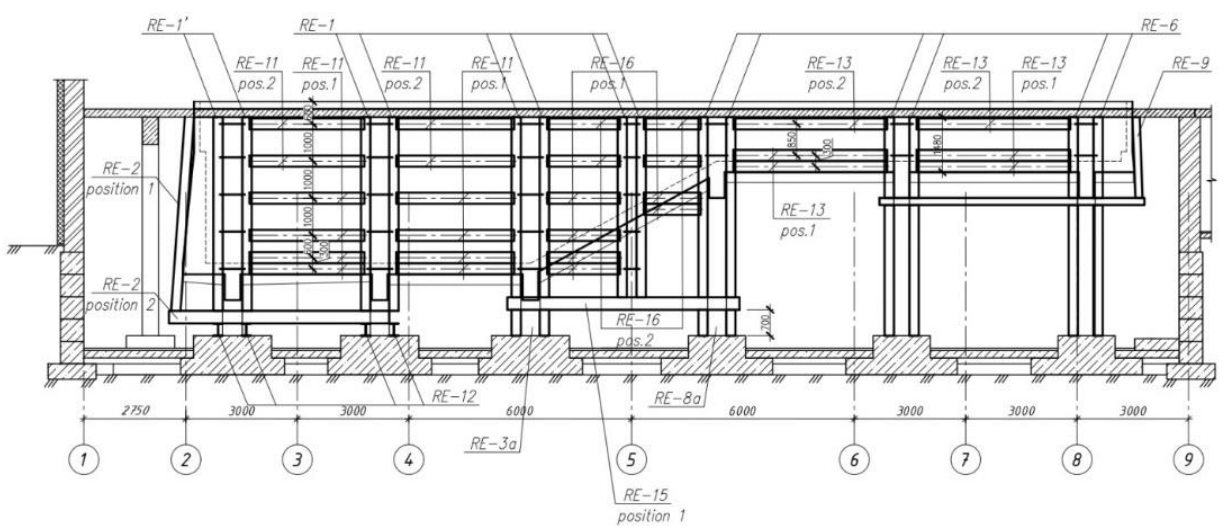

Fig. 8. View 1 (longitudinal). 


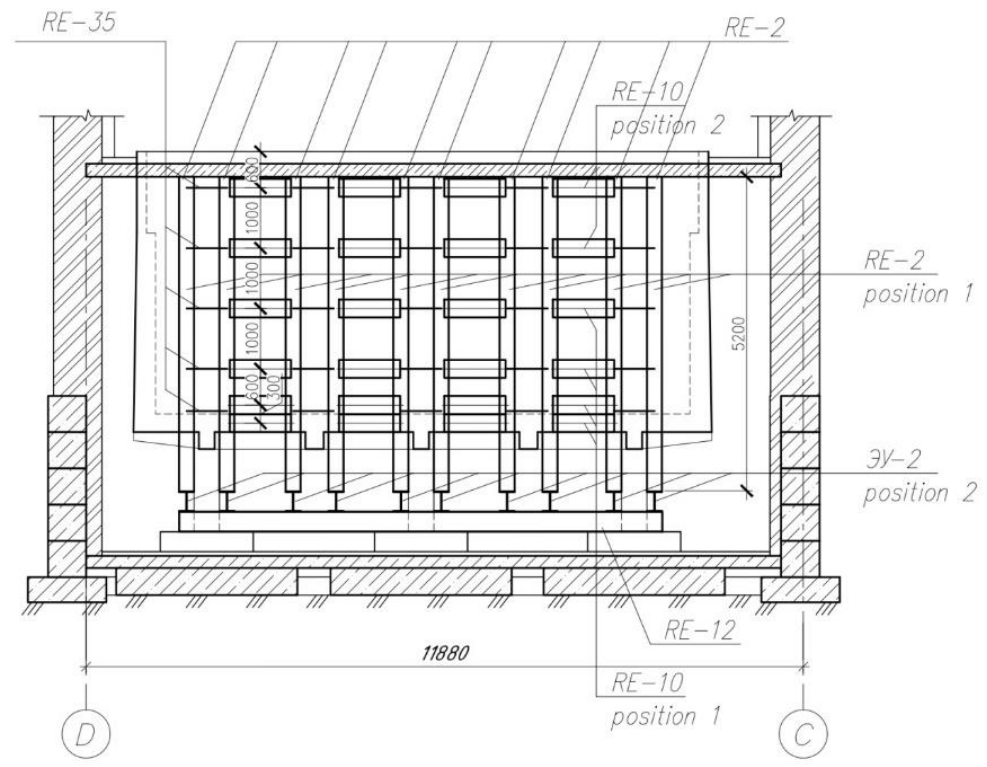

Fig. 9. View 2 (end, deep-water side).

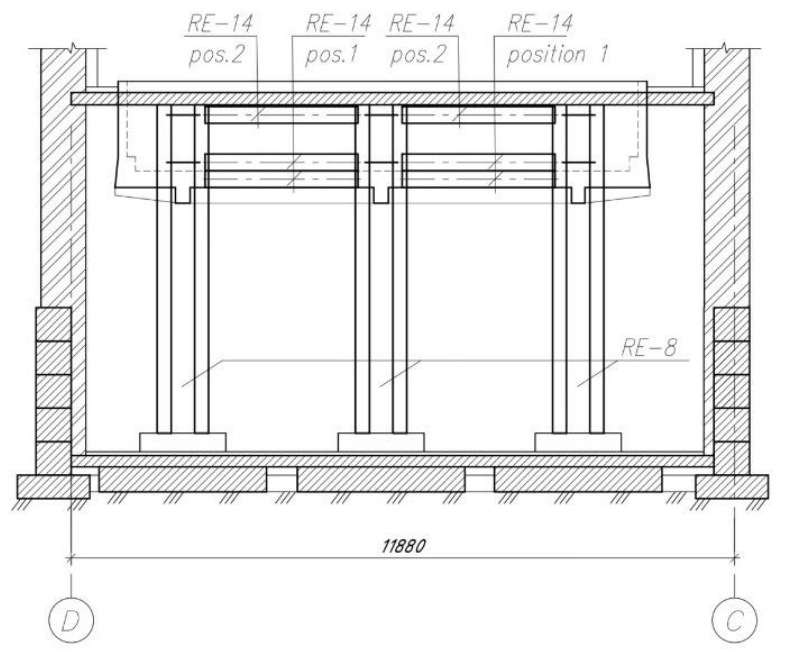

Fig. 10. View 3 (end, shallow water side). 
Calculations of the pool bowl foundations were carried out, taking into account the additional loads from the reinforcement structures and repair compositions. Calculations of building structures were performed, including the calculation for the limiting state of the first and second group of monolithic reinforced concrete structure of the pool bowl (together with reinforcement structures) in accordance with sections 5 and $8 \mathrm{BC}$ 63.13330.2018 - for operational loads and loads during hydraulic tests, in accordance with art. 15.20 BC 31.13330.2012.

Due to the fact that the category of the pool bowl technical state according to the survey results is emergency, and the adopted reinforcement option entails a change in the stressstrain state of the supporting structures (i.e., the design scheme changes), the work on the pool restoration should be classified not as capital repair, but as reconstruction (GOST 31937-2011, UPC RF №190-FL, Art. 1, Art. 14). Today, this is one of the most common problems that have arisen in the process of developing design documentation for the overhaul of an object, which puts the designers in the "to-peak".

\section{Conclusion}

For the implementation of design solutions to strengthen the basin of the pool, other methods can also be applied, for example, using modern reinforcement methods using composite materials [9-11]. This will increase the rigidity of each structure and the bowl as a whole.

the development and implementation of these design solutions using modern methods will qualify the design of the pool bowl in a working condition and will return the ability to perceive all the loads acting on it.

\section{References}

1. Urban Planning Code of the Russian Federation.

2. P.A. Serbinovsky, D.R. Mayilyan, Engineering Journal of Don 2 (41), 70 (2016)

3. D.R. Mailian, P.P. Polskoy, S.V. Georgiev, Engineering Journal of Don 2 (25), 98 (2013)

4. V.N. Aksenov, D.R. Mayilyan, Concrete and reinforced concrete 6, 5-8 (2008)

5. A.M. Mkrtchyan, V.N. Aksenov, D.R. Mailyan, A.M. Blyagoz, M.V. Smorgunova, New technologies 11, 127-132 (2013)

6. D. Mailyan, V. Aksenov, N. Aksenov, Advances in Intelligent Systems and Computing 692, 536-542 (2017)

7. BC 13-102-2003 "Rules for the inspection of load-bearing building structures of buildings and structures". 
8. GOST 31937-2011 "Buildings and structures. Rules for inspection and monitoring of technical condition".

9. P.P. Polskoy, D.R. Mailyan, Engineering Journal of Don 4 (43), 169 (2016)

10. P.P. Polskoy, S.V. Georgiev, Engineering Journal of Don 4 (47), 241 (2017)

11. P. Polskoy, D. Mailyan, S. Georgiev, V. Muradyan, E3S Web of Conferences 02060 (2018) 